\title{
Studi Pengaruh Ukuran Partikel dan Penambahan Perekat Tapioka Terhadap Karakteristik Biopelet Dari Kulit Coklat (Theobroma Cacao l.) Sebagai Bahan Bakar Alternatif \\ TERBARUKAN
}

Study Effect of Particle Size and Tapioca Starch Addition on Biopelet Characteristic from Cacao Shell (Theobroma cacao L.) as Alternative Renewable Fuel

\author{
Retno Damayanti ${ }^{1)}$, Novia Lusiana ${ }^{1)}$, Joko Prasetyo ${ }^{1)}$ \\ Staf Pengajar Keteknikan Pertanian, Fakultas Teknologi Pertanian, Universitas Brawijaya, \\ Jl. Veteran, Ketawanggede, Kec. Lowokwaru, Kota Malang, 65145 Jawa Timur \\ Email : damayanti@ub.ac.id
}

\begin{abstract}
ABSTRAK
Limbah kulit kakao dalam jumlah banyak (75\% dari dari bahan baku pengolahan coklat) menjadi permasalahan tersendiri pada industri pengolahan coklat. Pemanfaatan kulit kakao berpotensi sebagai bahan bakar alternatif terbarukan karena ketersediaanya yang cukup melimpah dan pemanfaatannya yang belum maksimal. Pemanfaatan kulit kakao sebagai biopelet menjadi salah satu solusi pengolahan kulit kakao yang tepat untuk menghindari masalah baru bagi lingkungan yaitu pembusukan karena adanya penguraian karbon oleh mikroorganisme. Karakteristik kulit kakao yang mengandung lignin sebesar 1219\% menjadikan kulit kakao sangat potensial digunakan sebagai biopelet. Tujuan dari penelitian ini adalah mengetahui pengaruh ukuran partikel dan penambahan tapioka pada pembuatan biopelet kulit kakao, menentukan perlakuan optimal serta melakukan uji karakteristik fisik dan kimia biopelet kulit kakao. Metode eksperimen dengan pengolahan data secara deskriptif kuantitatif dengan membandingkan hasil uji karakteristik biopelet dari variasi ukuran mesh dan variasi kadar perekat (tepung tapioka) untuk mencari kualitas biopelet yang optimal. Perlakuan optimal terjadi pada ukuran partikel biopelet 20 mesh dengan penambahan perekat tapioka $20 \%$ dengan kadar air 3,52\%, kadar abu 6,99\%, dan kerapatan 0,87 $\mathrm{g} / \mathrm{cm}^{3}$ dan nilai kalor 3090,1 kal/g. Pengembangan penelitian dapat diarahkan kepada penambahan campuran bahan baku yang mempunyai nilai kalor tinggi sehingga dapat meningkatkan nilai kalor biopelet yang dihasilkan.
\end{abstract}

Kata kunci : biopelet, kakao, kadar air, kadar abu, nilai kalor

\section{ABSTRACT}

Waste of cocoa shellsare becoming a problem in cocoa processing industry in large quantities (75\% of raw material). Cocoa shells are potential as a renewable alternative fuel because of its availability and not exploited yet. The utilization of cocoa shells as biopelet is one of method to convert a cocoa shell as a renewable alternatiive fuel. Cocoa shells characteristics is containing lignin by 12-19\% that makes it very potentially used as biopelet. The experimental method was using quantitative descriptive analysis to compare the result of all variants (cacao size and tapioca starch variation) biopelet characteristic test. The result shows that the optimal treatment occurson 20 mesh particle size with 20\% tapioca starch addition tapioca, water content of 3,52\%, ash content of $6,99 \%$, and a density of $0,87 \mathrm{~g} / \mathrm{cm} 3$ and 3090,1 calorific value cal / g. Development of research is by mixture cacao shell with other raw materials with high calorific value so could increasing the calorific value of biopelet.

Keywords: biopelet, cocoa, water content, ash content, heating value

Diterima : 16 Desember 2017; Disetujui : 16 Maret 2017; Online Published : 25 Juli 2017

DOI : 10.24198/jt.vol11n1.6 


\section{PENDAHULUAN}

Peningkatan pemanfaatan limbah menjadi produk baru yang memiliki nilai ekonomis tinggi merupakan salah satu solusi untuk mengurangi jumlah residu akibat industri. Salah satu industri pertanian yang memiliki permasalahan limbah adalah porsi limbah kulit kakao yang cukup besar yaitu sebesar $75 \%$ dari proporsi jumlah bahan baku (Suparjo et al, 2011). Hal ini juga terjadi pada pemasok/petani yang memasok biji coklat untuk industri pengolahan coklat Kampoeng Coklat yang berada di wilayah Kabupaten Blitar, di Jalan Banteng Blorok 18 Desa Plosorejo Kademangan Blitar.

Pemanfaatan limbah kulit kakao di area tersebut sebatas sebagai bahan bakar langsung. Pemanfaatan bahan bakar langsung mempunyai kelemahan yaitu bahan bakar dari biomassa masih memiliki sifak fisik yang buruk, seperti: kerapatan energi yang rendah dan permasalahan penanganan, penyimpanan, serta transportasi (Saptoadi, 2006).

Biopelet atau pelet yang berasal dari biomassa dikonversi dan dapat dimanfaatkan sebagai energi bahan bakar menggunakan teknik densifikasi. Teknik ini bertujuan untuk meningkatkan densitas (kerapatan) dari bahan dan memudahkan penyimpanan serta pengangkutan. Konversi biomassa dapat menaikkan nilai kalori per unit volume, mudah disimpan dan diangkut, mempunyai ukuran, dan kualitas yang seragam dari biopelet yang dihasilkan.Faktor utama yang mempengaruhi kekuatan dan ketahanan dari pelet adalah bahan baku, kadar air, ukuran partikel, kondisi pengempaan, penambahan perekat, alat densifilasi, dan perlakuan setelah proses produksi (Lehmann et al. 2012).

Salah satu parameter penentu kualitas bahan bakar biomassa adalah nilai kalor yang dihasilkan pada proses pembakaran. Peningkatan nilai kalor bahan bakar biomassa dapat dilakukan melalui proses densifikasi. Densifikasi merupakan proses pengkompakan residu menjadi produk yang mempunyai densitas lebih tinggi daripada bahan baku aslinya (Bhattacharya, 1998).
Campuran cangkang sawit dan serbuk gegajian sengon ditingkatkan nilai manfaatnya dengan mengolahnya sebagai bahan baku biopelet. Nilai kalor tertinggi diperoleh pada serbuk gergaji sengon $0 \%$ sebesar $5452,30 \mathrm{kkal} / \mathrm{kg}$. Pada penambahan $25 \%$ serbuk gergaji sengon diperoleh nilai kalor tertinggi sebesar 4870,27 $\mathrm{kkal} / \mathrm{kg}$ dibandingkan dengan campuran yang lain yaitu $50 \%$ sebesar $4403,08 \mathrm{kkal} / \mathrm{kg}$ dan $75 \%$ sebesar $4362,83 \mathrm{kkal} / \mathrm{kg}$ terhadap cangkang sawit (Saragih, 2013).

Penambahan arang sekam padi dalam biopelet serbuk sengon dan arang sekam padi dapat menurunkan kadar air, meningkatkan kadar abu dan meningkatkan nilai kalor. Meskipun terjadi peningkatan nilai kalor, namun penambahan arang sekam padi menyebabkan kualitas terbaik yaitu pada $100 \%$ serbuk sengon memiliki nilai kerapatan $1,21-1,26 \mathrm{~g} / \mathrm{cm}^{3}$, nilai keteguhan tekan $14,33 \mathrm{~kg} / \mathrm{cm}^{2}$, nilai kalor 4751,50 - 6217,12 kal/gr, kadar abu 11,56 - 19,14\%, kadar air 3,76-8,53\% (Winata, 2013).

Limbah daun tebu dimanfaatkan menjadi biopelet menghasilkan kondisi optimal dengan perlakuan suhu pengempaan $250{ }^{\circ} \mathrm{C}$ selama 20 menit. Pengempaan dengan kondisi tersebut menghasilkan biopelet dengan kadar air 3,41\%, kadar abu $12,19 \%$, kuat tekan $119,22 \mathrm{kgf} / \mathrm{cm}^{2}$ dan kalor $4490 \mathrm{kkal} / \mathrm{kg}$. Pembuatan biopelet daun tebu mampu menaikkan nilai kalor daun tebu sebesar 36,84\% (Hartadi, 2015).

Tujuan dari penelitian ini adalah mengetahui pengaruh ukuran partikel dan penambahan tapioka pada pembuatan biopelet kulit kakao, menentukan perlakuan optimal serta melakukan uji karakteristik fisik dan kimia biopelet kulit kakao.

\section{METODOLOGI PENELITIAN}

\section{Waktu dan Tempat}

Penelitian ini dilaksanakan di Laboratorium Mekatronik Alat dan Mesin Agroindustri di Jurusan Keteknikan Pertanian Univeristas Brawijaya (UB), Bulan Agustus sampai dengan November 2016. 


\section{Bahan dan Alat}

Bahan uji penelitian adalah kulit coklat, perekat tapioca sebagai bahan tambahan untuk meningkatkan ikatan antar partikel biopelet dan air untu mencampur bahan uji dengan perekat. Alat yang digunakan pada penelitian ini yaitu, disk mill untuk menggiling bahan baku agar seragam atau menghaluskan material bahan baku, ayakan 20, 40, 60 dan 80 mesh berfungsi memisahkan bahan berdasar ukuran mesh, hand press dan ring die pellet mill untuk mencetak biopelet, oven untuk mengurangi kadar air bahan dan biopelet, Timbangan Mettler Toledo untuk mengukur massa bahan, furnace untuk menguji kadar abu biopelet, bomb calorimeter untuk menguji nilai kalor biopelet.

\section{Disain Penelitian}

Disain penelitian menggunakan rancangan acak kelompok dengan dua factorial yaitu variasi ukuran mesh $(A)$ dengan 4 variasi yaitu 20 mesh, 40 mesh, 60 mesh dan 80 mesh dan variasi tapioka $(\mathrm{T})$ dengan tiga variasi $0 \%, 5 \%$ dan $10 \%$. Kombinasi perlakuan ukuran ayakan dan kadar perekat dapat dilihat pada Tabel 1.

Tabel 1. Kombinasi Perlakuan

\begin{tabular}{lccc}
\hline Ayakan & \multicolumn{3}{c}{ Perekat Tapioka (T) } \\
\cline { 2 - 4 } (A) & 0\%(T1) & $10 \%(\mathrm{~T} 2)$ & 20\%(T3) \\
\hline 20 mesh (A1) & A1T1 & A1T1 & A1T1 \\
40 mesh (A2) & A2T2 & A2T2 & A2T2 \\
60 mesh (A3) & A3T3 & A3T3 & A3T3 \\
80 mesh (A4) & A4T4 & A4T4 & A4T4 \\
\hline
\end{tabular}

Tahapan Penelitian

\section{Persiapan Bahan}

Bahan utama dalam peneltian ini adalah kulit dari buah kakao (coklat). Bahan diperoleh dari kebun coklat lebih tepatnya di tempat wisata Kampung coklat yang berada di wilayah Kabupaten Blitar, di Jalan Banteng Blorok 18 Desa Plosorejo Kademangan Blitar. Kulit kakao yang digunakan berasal dari buah kakao yang telah masak atau dipanen dan dipisahkan dari daging buahnya. Sebelum dilakukan penggilingan, kulit kakao dikeringkan terlebih dahulu agar tidak terjadi penggumpalan saat digiling.

\section{Pembuatan Biopelet}

Setelah kulit kakao dikeringkan dilakukan proses pengecilan ukuran dengan digiling menggunakan alat disk mill. Pengecilan ukuran ini bertujuan untuk menghaluskan bahan dan mempermudah proses densifikasi biopelet. Pengayakan menggunakan ayakan dengan ukuran 20, 40, 60 dan 80 mesh. Pengayakan ini bertujuan untuk menyeragamkan bahan kulit kakao yang telah digiling.

Pencetakan biopelet dengan ring pelet dengan ukuran lubang pengeluaran pelet yaitu diameter $1 \mathrm{~cm}$ dan panjang $1 \mathrm{~cm}$. Setelah dihasilkan biopelet, kemudian dikeringkan menggunakan oven dengan suhu $60^{\circ} \mathrm{C}$ selama \pm 3 jam atau mencapai KA $10-15 \%$. Sifat atau karakteristik fisik biopelet akhir yang diukur adalah kadar air, kadar abu, densitas dan nilai kalor. Serta dilakukan pengujian efesiensi dari masing-masing perlakuan pada biopelet.

Pengujian Kualitas Biopelet

\section{Kadar Air}

Perhitungan untuk kadar air menggunakan Persamaan 1. Tahapan pengujian adalah cawan yang akan digunakan dioven selama 30 menit pada suhu 100-105 ㄷ, Cawan didinginkan dalam desikator untuk menghilangkan uap air dan ditimbang (A), sampel ditimbang sebanyak $2 \mathrm{~g}$ dalam cawan yang sudah dikeringkan (B), Sampel didinginkan dalam desikator selama 30 menit dan ditimbang $(C)$ dan tahap ini diulangi hingga bobot yang konstan (AOAC, 2005).

$\%$ kadar air $=\frac{B-C}{B-A} \times 100 \%$

A sebagai berat cawan kosong dinyatakan (gram), B sebagai berat cawan + sampel awal dinyatakan (gram), C sebagai berat cawan + sampel kering (gram).

\section{Kadar Abu}

Prosedur analisa kadar abu adalah sebagai berikut (AOAC, 2005) adalah cawan yang akan 
digunakan dioven selama 30 menit pada suhu 100-105 ${ }^{\circ} \mathrm{C}$, cawan didinginkan dalam desikator untuk menghilangkan uap air dan ditimbang (A), Sampel ditimbang sebanyak $2 \mathrm{~g}$ dalam cawan yang sudah dikeringkan (B), Sampel dibakar di atas nyala pembakar sampai tidak berasap, pengabuan di dalam tanur bersuhu $550-600^{\circ} \mathrm{C}$ sampai pengabuan sempurna, sampel yang sudah diabukan didinginkan dalam desikator dan ditimbang (C). Perhitungan prosentase kadar abu menggunakan Persamaan 2.

$\%$ kadar abu $=\frac{\mathrm{C}-\mathrm{A}}{\mathrm{B}-\mathrm{A}} \times 100 \%$

A sebagai berat cawan kosong dinyatakan (gram), B sebagai berat cawan + sampel awal (gram), C sebagai berat cawan + sampel kering (gram).

\section{Nilai Kalor}

Prosedur analisa nilai kalor atau adalah sebagai berikut (Annual Book of ASTM Standards, 1989) adalah Sampel ditimbang sebanyak 0,15 gram, diletakkan dalam cawan platina dan ditempatkan pada ujung tangkai penyala yang sudah dipasang kawat penyala. Sampel dimasukkan ke dalam tabung bom dan ditutup dengan erat. Oksigen diisikan ke dalam tabung dengan tekanan 30 bar dan dimasukkan ke dalam tabung kalorimeter yang sudah diisikan air pendingin sebanyak $1250 \mathrm{ml}$.

Kalorimeter ditutup dan termometer dipasang pada tutup kalorimeter. Pengaduk air pendingin dihidupkan selama 5 menit dan dicatat temperatur yang tertera pada termometer. Penyalaan dilakukan dan diaduk terus air pendingin selama 5 menit, kemudian dicatat kenaikan suhu pada termometer. Perhitungan nilai kalor dapat dihitung menggunakan Persamaan 3.

$$
\text { Nilai Kalor }=\left(\frac{\mathrm{Wx}(\mathrm{t} 2-\mathrm{t} 1)}{\mathrm{A}}\right)-\mathrm{B}
$$

W sebagai nilai air dari alat kalorimeter, $\mathrm{t} 1$ sebagai suhu mula-mula, t2 sebagai suhu setelah pembakaran, A adalah bobot contoh, B adalah koreksi panas pada kawat besi.

\section{HASIL DAN PEMBAHASAN}

\section{Karakteristik Kulit Coklat}

Biopelet dibuat dari limbah kulit coklat dengan penambahan perekat tapioka sebanyak $0 \%, 10 \%$ dan $20 \%$. Peletisasi dilakukan dengan menggunakan hand press yang dilengkapi dengan ring die pelet dengan ukuran diameter dies $10 \mathrm{~cm}$ dan terdiri dari lubang-lubang pada dies dengan diameter $10 \mathrm{~mm}$.

Pencetakan dibantu dengan tekanan dari atas (ulir pegangan) dan dari bawah (hidrolis 20 ton) pada Gambar 1. Ukuran butiran biopelet juga bervariasi yaitu 20 mesh, 40, 60 dan 80 mesh (Gambar 2). Biopelet yang dihasilkan mempunyai ukuran diameter $10 \mathrm{~mm}$ dan panjang berkisar antara $10-11 \mathrm{~cm}$. Panjang biopelet yang digunakan yaitu $1 \mathrm{~cm}$. dimana pemotongan dilakukan secara manual. Penentuan ukuran biopelet diameter $1 \mathrm{~cm}$ panjang $8-10 \mathrm{~mm}$ bertujuan untuk memudahkan proses pengeringan akhir.

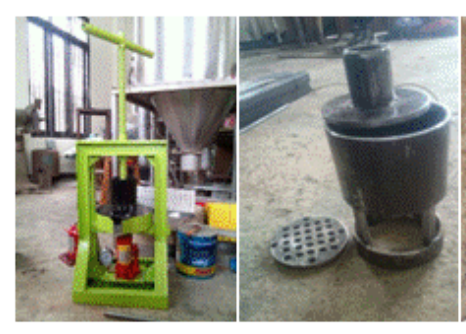

(a) (b)

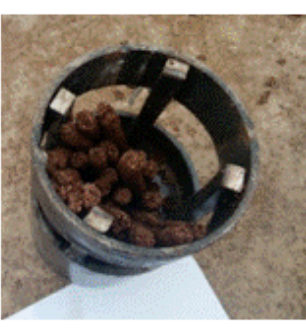

(c)
Gambar 1. Alat Pencetak Biopelet (a) alat penekan, (b) alat pencetak, (c) hasil cetakan biopelet

Hasil cetakan biopelet tanpa perekat (Gambar 2a) secara fisik permukaannya lebih kasar dan porous dibandingkan dengan yang menggunakan perekat (Gambar 2b dan 2c) sehingga lebih mudah hancur apabila diberikan tekanan. Semakin tinggi perekat yang ditambahkan ke dalam serbuk kulit coklat akan menghasilkan biopelet yang lebih padat dan pada penambahan perekat 20\% (Gambar 2c), akan dihasilkan biopelet bertesktur keras dan padat 

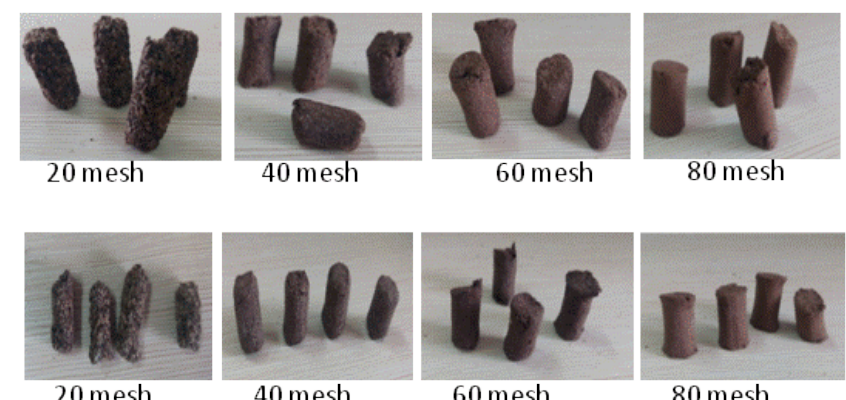

40 mesh

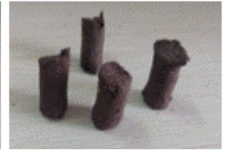

60 mesh

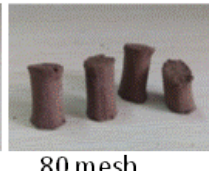

80 mesh
Gambar 2. Hasil Cetakan Biopelet pada Berbagai Perlakuan (a) biopelet tanpa perekat, b) biopelet dengan perekat tapioka $10 \%$, (c) biopelet denga perekat tapioka $20 \%$

Standar kualitas pelet dibeberapa negara dan berdasarkan Badan Standarisasi Nasional (BSN) disajikan pada Tabel 2 berikut ini :

Tabel 2. Kualitas pelet beberapa standar biopelet

\begin{tabular}{llccc}
\hline \multirow{2}{*}{ Parameter } & \multirow{2}{*}{ Satuan } & \multicolumn{3}{c}{ Standar } \\
\cline { 3 - 5 } & & Amerika & Perancis & BSN \\
\hline Diameter & $\mathrm{mm}$ & $6,35-7,94$ & $6-16$ & - \\
Panjang & $\mathrm{mm}$ & $<3,81$ & $10-50$ & - \\
Kerapatan & $\mathrm{g} / \mathrm{cm}^{3}$ & $>0,64$ & $>1,15$ & $>0,8$ \\
Kadar Air & $\%$ & - & $\leq 15$ & 12 \\
Kadar Abu & $\%$ & $<3($ standar) & & \\
& & (premium) & $\leq 6$ & $<1,5$ \\
Nilai Kalor & $\mathrm{cal} / \mathrm{g}$ & $>4579,2$ & $>4056$ & $>$ \\
\cline { 3 - 5 } & & & 4000
\end{tabular}

Sumber: ${ }^{\text {(a) }} \mathrm{PFI}$ (2007) ; ${ }^{\text {(b) }}$ Douard (2007) ; BSN (2014)

Karakterisasi pelet kulit coklat bergantung pada proporsi penambahan perekat tapioka. Penambahan tapioka berpengaruh terhadap peningkatan kualitas bioepelet yang dihasilkan. Kualitas biopelet yang diuji disajikan pada Tabel 3.

Data hasil uji karakterisasi biopelet diatas akan dibandingkan dengan standar kualitas biopelet untuk mengetahui perlakuan mana yang memberikan kualitas optimal (mendekati dengan standar kualitas biopelet). Pengolahan data terhadap uji pengaruh nyata antar perlakuan tidak dilakukan dikarenakan ini merupakan penelitian awal untuk mengetahui perlakuan optimal terhadap hasil kualitas biopelet.
Tabel 3. Karakterisasi biopelet hasil pengujian

\begin{tabular}{lclll}
\hline & \multicolumn{4}{c}{ Parameter } \\
\cline { 2 - 5 } Perlakuan & $\begin{array}{c}\text { Kadar } \\
\text { air } \\
(\%)\end{array}$ & $\begin{array}{c}\text { Kadar } \\
\text { abu } \\
(\%)\end{array}$ & $\begin{array}{c}\text { Kerapatan } \\
\left(\mathrm{g} / \mathrm{cm}^{3}\right)\end{array}$ & $\begin{array}{c}\text { Nilai } \\
\text { kalor } \\
(\mathrm{kal} / \mathrm{g})\end{array}$ \\
\hline A1T1 & 6,94 & 9,43 & 0,90 & 3727,30 \\
A2T1 & 7,07 & 10,36 & 0,90 & 3706,30 \\
A3T1 & 6,58 & 11,77 & 0,85 & 1206,70 \\
A4T1 & 6,81 & 11,30 & 1,02 & 1188,70 \\
A1T2 & 4,69 & 7,23 & 1,06 & 1244,10 \\
A2T2 & 6,81 & 12,23 & 0,92 & 1220,60 \\
A3T2 & 7,38 & 11,58 & 0,97 & 1085,30 \\
A4T2 & 7,21 & 10,18 & 0,99 & 917,50 \\
A1T3 & 3,52 & 6,99 & 0,87 & 3909,10 \\
A2T3 & 2,82 & 10,33 & 1,05 & 3727,60 \\
A3T3 & 2,38 & 8,50 & 0,81 & 1153,70 \\
A4T3 & 2,51 & 8,54 & 1,01 & 1115,60 \\
\hline
\end{tabular}

\section{Kadar Air}

Kadar air merupakan salah satu parameter penetuan kualitas biopelet yang berpengaruh terhadap nilai kalor pembakaran, kemudahan menyala, daya pembakaran dan jumlah asap yang dihasilkan selama pembakaran. Tingginya kadar air bioepelet dapat menurunkan nilai kalor pembakaran, menyebabkan proses penyalaan menjadi lebih sulit dan menghasilkan banyak asap pada proses pembakaran (Rahman, 2011). Kadar air awal kulit coklat berkisar antara $50-70 \%$. Kulit coklat selanjutnya mengalami proses pengeringan sampai mencapai kadar air $<12 \%$ dengan rendemen berkisar antara 20\%. Gambar 3 menunjukkan nilai kadar air pada masing-masing sampel.

Biopelet yang telah dicetak dikeringkan dengan suhu $70{ }^{\circ} \mathrm{C}$ dengan lama pengeringan 3 jam. Berdasarkan hasil penelitian, nilai kadar air yang diperoleh pada biopelet berkisar antara 2,51 - 7,38\%. Kadar air terendah diperoleh pada perlakuan dengan penambahan perekat tapioka $20 \%$ tetapi kadar air tersebut masih memenuhi standar biopelet dari Negara Perancis (ITEBE) dibawah $15 \%$ dan standar Indonesia dibawah $12 \%$. Kadar air biopelet memiliki nilai yang berbanding lurus dengan persentase perekat tapioka yang digunakan. 
Semakin tinggi persentase perekat tapioka yang digunakan, kadar air yang dihasilkan lebih rendah. Penambahan perekat tapioka diduga mampu menyerap air yang terkandung dalam bahan, sehingga kandungan air pada bahan cepat berkurang selama proses pengeringan. Penambahan air dan penekanan selama proses pencetakan berpengaruh terhadap kadar air biopelet yang dihasilkan sebelum dicetak. Penambahan air yang tidak seimbang pada masing-masing perlakuan mempengaruhi massa dari biopelet sehingga kadar air yang dihasilkan menjadi tidak stabil. Variasi kadar air karena pengaruh penambahan tapioca dapat dilihat pada Gambar 3.

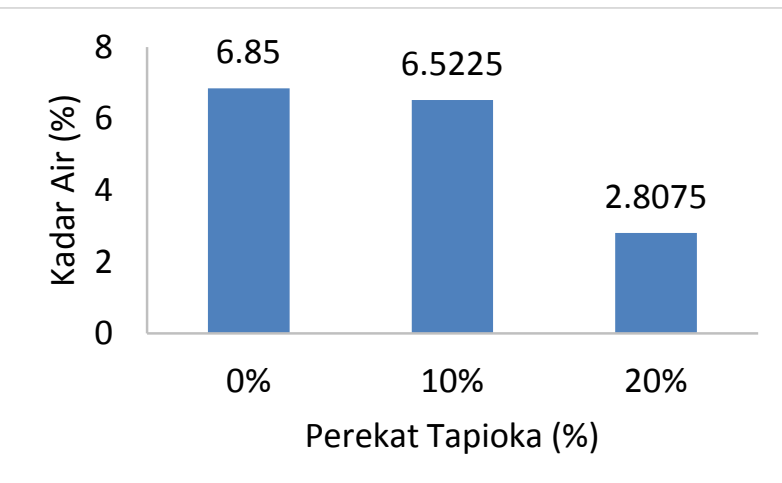

Gambar 3. Interval Kadar Air Pengaruh Penambahan Perekat

Ali et al. (2010) menyatakan air yang ditambahkan selama proses pencampuran bungkil picung dan bahan tambahan berpengaruh pada peningkatan kadar air biopelet. Selain itu, tekanan saat pencetakan juga dapat mempengaruhi hasil kandungan air pada biopelet. Tekanan yang tinggi dapat menyebabkan biopelet semakin padat, kerapatan tinggi, halus dan seragam, sehingga partikel biomassa dapat saling mengisi pori - pori yang kosong serta menurunkan molekul air yang dapat menempati pori - pori tersebut (Rahman 2011).

\section{Kadar Abu}

Kadar abu merupakan bahan sisa proses pembakaran yang tidak memiliki unsur karbon atau nilai kalor. Komponen utama abu dalam biomassa berupa kalsium, potassium, magnesium, dan silika (Christanty, 2014) yang berpengaruh terhadap nilai kalor pembakaran.Semakin banyak silika pada biopelet, maka kualitas biopelet akan semakin rendah. Kadar abu merupakan salah satu parameter yang penting karena bahan bakar tanpa abu (seperti minyak dan gas) memiliki sifat pembakaran yang lebih baik (White dan Paskett 1981 dalam Zamizar 2009).

Nilai kadar abu yang dihasilkan berkisar antara $8,5 \%-12,23 \%$. Kadar abu tertingi pada perlakuan biopelet dengan ukuran partikel 40 mesh. Sedangkan kadar abu terendah terdapat pada biopelet dengan ukuran partikel 20 mesh. Berdasarkan persyaratan standar mutu kadar abu untuk biopelet adalah maksimal 1,5\%, nilai kadar abu yang dihasilkan untuk semua perlakuan belum memenuhi standar mutu yang berlaku. Penambahan tapioka dapat menurunkan nilai kadar abu. Semakin tinggi kadar abu, maka kualitas biopelet semakin rendah. Hal ini akan berpengaruh pada panas yang dihasilkan semakin rendah karena adanya penumpukan abu yang tidak terbakar.

Jumlah abu yang dihasilkan dipengaruhi oleh jenis bahan biomassa yang digunakan dan penyusunnya, salah satunya adalah silika. Silika merupakan salah satu komponen fly ash (abu terbang) yang paling dominan jumlahnya yaitu sekitar 30-36\%. Menurut Merdekawani dan Kasmiran (2013) kandungan Abu dalam kulit kakao sebesr $12,2 \%$. Semakin tinggi kadar silika pada suatu bahan biomassa, maka abu yang dihasilkan dari proses pembakaran akan semakin tinggi (Rahman 2011). Kadar abu yang tinggi beresiko terbentuknya endapan atau kerak mineral pada saat pembakaran, sehingga mengakibatkan permukaan tungku kotor, korosi, dan konduktifitas termal serta kualitas pembakaran menurun. Kadar abu yang semakin rendah akan menghasilkan biopelet yang semakin baik (Christanty, 2014) 


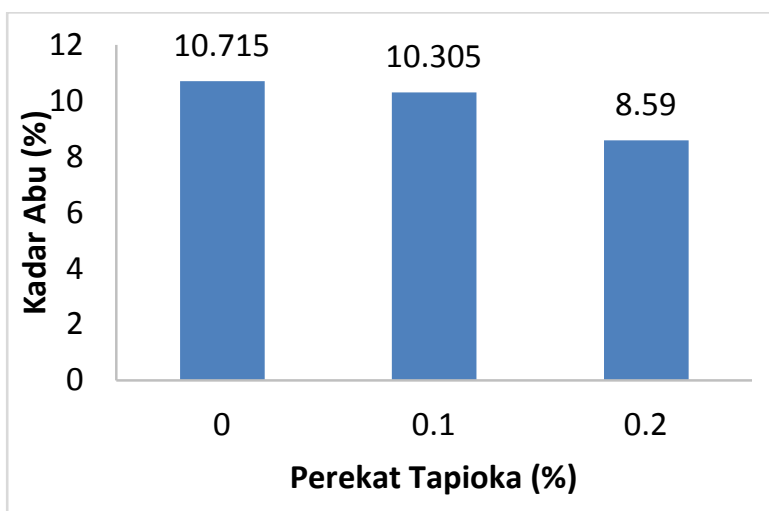

Gambar 4. Interval Kadar Abu Pengaruh Penambahan Perekat

\section{Kerapatan}

Kerapatan merupakan perbandingan antara massa kayu dengan volume kayu (Haygreen dan Bowyer, 1996). Nilai kerapatan biopelet yang tinggi dapat memudahkan dalam hal penyimpanan, penanganan, dan transportasi biopelet (Adapa et al. 2007 dalam Nurwigha 2012). Tinggi-rendahnya kerapatan pada biopelet dipengaruhi oleh tekanan pada saat pengepresan.

Nilai kerapatan yang dihasilkan berkisar $0,85 \mathrm{~g} / \mathrm{cm}^{3}-1,05 \mathrm{~g} / \mathrm{cm}^{3}$. Kerapatan tertinggi pada biopelet dari kulit coklat dengan campuran tapioka $10 \%$. Sedangkan kerapatan terendah pada biopelet tanpa penambahan tapioka (0\%). Kerapatan yang dihasilkan memenuhi standar biopelet Prancis (ITEBE), standar Amerika (PFI) dan standar Indonesia. Biopelet dari kulit coklat mengalami penurunan kerapatan pada penambahan tapioka $20 \%$. Hal ini menyatakan bahwa penambahan tapioka lebih dari $10 \%$ dapat menurunkan kerapatan biopelet. Semakin tinggi presentase perekat tapioka, tingkat homogenitas biopelet semakin redah dan nilai kerapatannya semakin kecil.

Menurut Winata (2013), menyatakan bahwa tinggi atau rendahnya nilai kerapatan dipengaruhi oleh berat jenis bahan tersebut. Berat jenis itu sendiri dipengaruhi oleh ukuran partikel dari bahan, dimana semakin kasar atau semakin besar ukuran partikel biopelet maka semakin kecil berat jenisnya, sehingga semakin kecil pula kerapatan yang dihasilkan. Pernyataan serupa juga dikemukakan oleh Munawar et al. (2014), beberapa faktor yang mempengaruhi kerapatan biopelet adalah partikel dan ukuran pelet, dimana ukuran partikel yang lebih kasar dan memiliki berat jenis lebih kecil menghasilkan kerapatan yang lebih kecil.

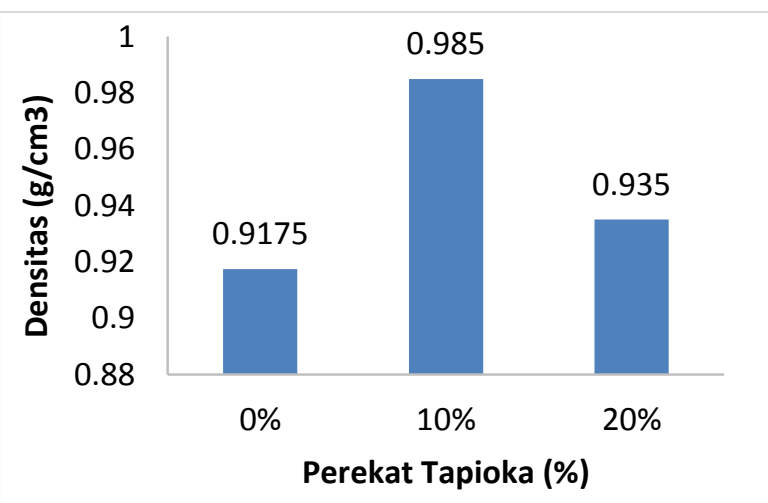

Gambar 5. Interval Nilai Kerapatan Pengaruh Penambahan Perekat

\section{Uji Kuat Tekan}

Parameter kuat tekan diuji untuk mengetahui ketahanan tekan dari suatu produk. Nilai kuat tekan yang tinggi suatu produk dapat memudahkan proses distribusi dan transportasi produk. Semakin tinggi nilai keteguhan tekan yang dihasilkan maka semakin kuat pula daya tekan dari produk. Pada biopelet terbuka, kuat tekan yang dihasilkan bervariasi. Biopelet yang diletakkan secara terbuka selama masa penyimpanan cenderung dapat mengalami perubahan ukuran karena biopelet dipengaruhi oleh fraksi lain dari udara lingkungan. Gambar 6 menunjukkan pengaruh ukuran butiran kulit coklat terhadap kuat tekan dan Gambar 7 menunjukkan pengaruh pemberian tapioca terhadap kuat tekan.

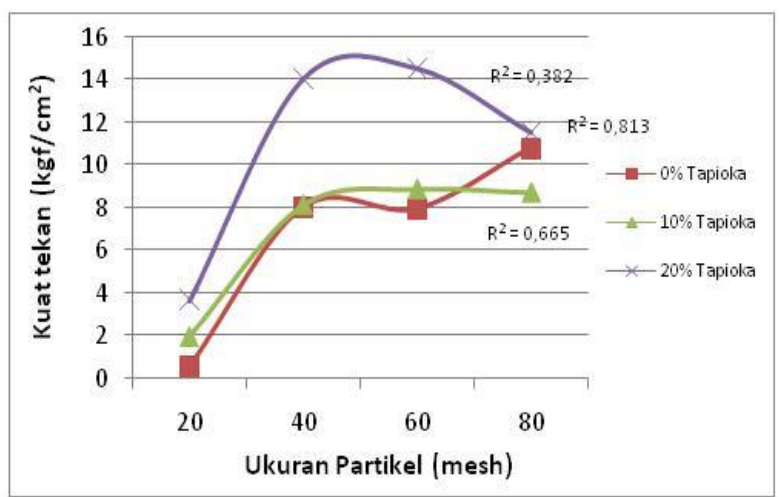

Gambar 6. Pengaruh Pemberian Tapioka terhadap Kuat Tekan 
Berdasarkan gambar diatas diperoleh hasil bahwa semakin kecil ukuran mesh yang digunakan pada sampel maka semakin besar kuat tekan, hal ini dapat dilihat pada nilai $R^{2}$ yang menunjukkan bahwa lebih dari $60 \%$ hasil kuat tekan pada pemberian $0 \%$ dan $10 \%$ tapioka menunjukkan kecenderungan meningkat (linier). Namun hal ini berbeda pada grafik pemberian tepung tapioka 20\% dimana pada ukuran 80 mesh menunjukkan penurunan kuat tekan yang sginificant, hal ini disebabkan pengaruh pemberian tapioka yang lebih besar pada ukura partikel paling halus sehingga kuat tekan biopelet mengalami penurunan.

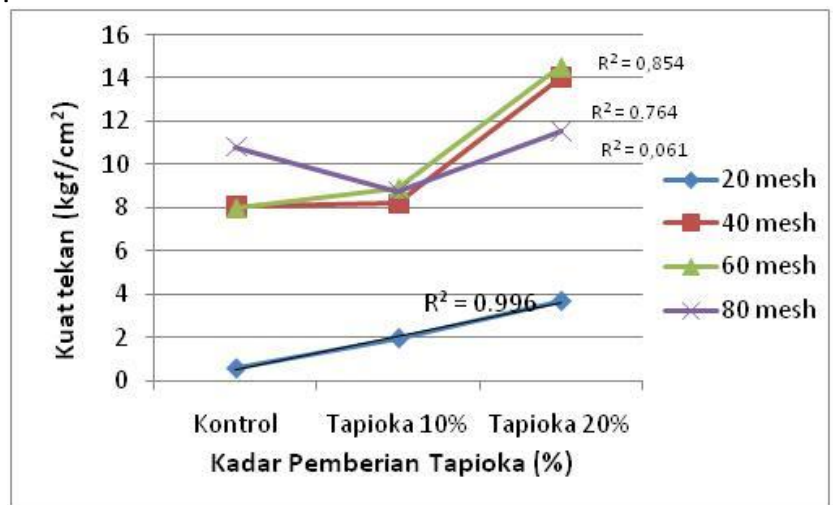

Gambar 7. Pengaruh Pemberian Tapioka terhadap Kuat Tekan

Hasil pengujian kuat tekan pada berbagai kadar pemberian tepung tapioka memiliki kecenderungan linier dimana pada sampel dengan ukuran 20,40, dan 60 mesh menunjukkan bahwa nilai $\mathrm{R}^{2}$ lebih dari $60 \%$. Hal ini menunjukkan bahwa sebanyak $60 \%$ data kuat tekan dapat dijelaskan oleh kadar tepung tapioka yang berarti bahwa semakin besar pemberian kadar tapioka dapat meningkatkan kuat tekan biopelet. Namun hasil yang berbeda ditunjukkan pada sampel pemberian $10 \%$ tapioka dengan ukuran 80 mesh, kuat tekan biopelet menurun dari pemberian $0 \%$ tapioka namun meningkat pada pemberian $20 \%$ tapioka.

Penentuan interval kuat tekan pada berbagai perlakuan diperoleh dari nilai standar deviasi pada data kuat tekan untuk setiap perlakuan. Grafik penentuan nilai interval kuat tekan pada setiap perlakuan dapat dilihat pada Gambar 8 dan Gambar 9.

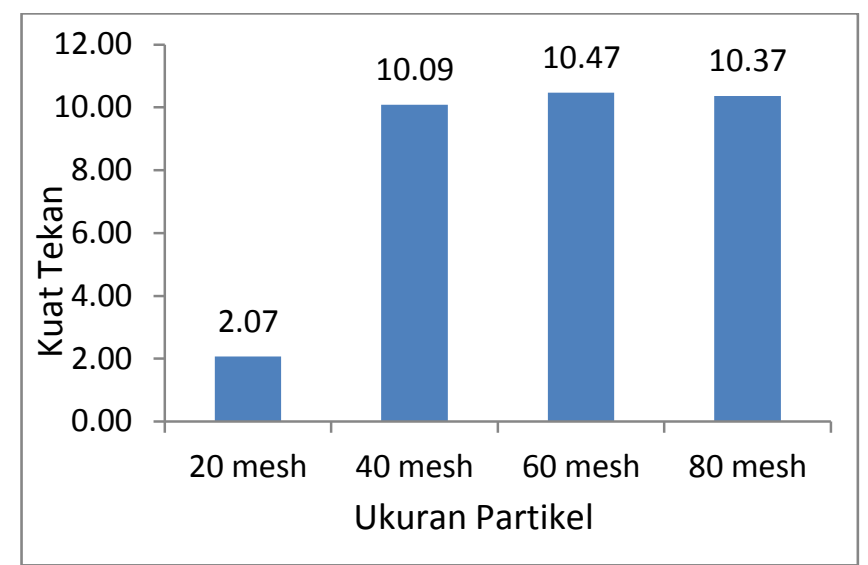

Gambar 8. Interval Kuat Tekan pada Pengaruh Ukuran Partikel Coklat

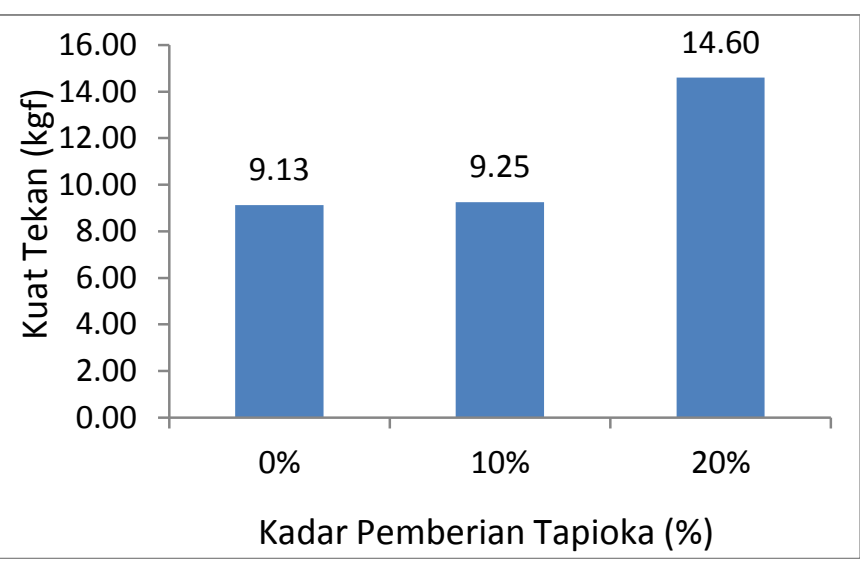

Gambar 9. Interval Kuat Tekan pada Pengaruh Pemberian Kadar Tapioka

Nilai interval untuk kuat tekan pada ukuran partikel 20 mesh dengan penambahan $0 \%, 10 \%$ dan $20 \%$ tapioka sebesar $0,7-3,44 \mathrm{kgf} / \mathrm{cm}^{2}$. Kuat tekan biopelet pada ukuran 40 mesh dengan penambahan $0 \%, 10 \%$ dan $20 \%$ tapioka berkisar antara $6,57-13,61 \mathrm{kgf} / \mathrm{cm}^{2}$. Kuat tekan biopelet pada ukuran 60 mesh dengan $0 \%, 10 \%$ dan $20 \%$ tapioka berkisar antara $6,48-14,46 \mathrm{kgf} / \mathrm{cm}^{2}$, kemudian untu kuat tekan biopelet 80 mesh mengahasilkan kuat tekan berkisar antara 8,06 $12,68 \mathrm{kgf} / \mathrm{cm}^{2}$. Dari hasil tersebut diperoleh kesimpulan bahwa perbedaan penentuan ukuran partikel memberikan hasil kuat tekan yang significant, sebagai contoh pada ukuran 20 mesh ke ukuran 40 mesh.

Nilai interval kuat tekan pada pemberian $0 \%$ tapioka dengan ukuran 20, 40, 60 dan 80 mesh diperoleh nilai antara 5,01-13,25 kgf/cm2. Kuat tekan dengan pemberian $10 \%$ tapioka dengan 
ukuran 20, 40, 60 dan 80 mesh berkisar antara $5,86-12,65 \mathrm{kgf} / \mathrm{cm}^{2}$, sedangkan pemberian $20 \%$ tapioka pada ukuran 20, 40, 60 dan 80 mesh diperoleh kuat tekan sebesar 9,46 - 19,74 $\mathrm{kgf} / \mathrm{cm}^{2}$. Hal ini menunjukkan bahwa pemberian kadar tapioka dapat meningkatkan kuat tekan biopelet.

\section{Nilai Kalor}

Parameter utama dalam menentukan kualitas bahan bakar biopelet adalah nilai kalor pembakaran. Nilai kalor didefenisikan sebagai panas yang dilepaskan dari pembakaran sejumlah kuantitas unit bahan bakar (massa) dimana produknya dalam bentuk ash, gas $\mathrm{CO}_{2}, \mathrm{SO}_{2}$, Nitrogen dan air, tidak termasuk air yang menjadi uap (vapor) (Patabang, 2011). Kalor yang semakin tinggi menunjukan kualitas bahan bakar yang semakin baik (Rahman 2011).

Nilai kalor tertinggi terjadi pada biopelet 20 mesh dengan penambahan perekat tapioka $20 \%$ yaitu 3909,1 kal/g dengan kandungan abu 6,9\% (terendah dari semua perlakuan). Nilai kalor terendah terjadi pada biopelet 80 mesh dengan penambahan perekat tapioka $10 \%$ yaitu 917,5 $\mathrm{kal} / \mathrm{g}$. Nilai kalor tertinggi adalah pada perlakuan biopelet dengan ukuran partikel 20 mesh dan terendah pada perlakuan biopelet dengan ukuran partikel 80 mesh. Berdasarkan standar mutu Amerika dan Perancis, nilai kalor belum memenuhi standar, nilai kalor biopelet yang dihasilkan belum memenuhi standar dikarenakan kadar abu biopelet yang dihasilkan terlalu tinggi. Hal ini diakibatkan mineral yang terkandung dalam biopelet banyak yang masih tertinggal dan tidak dapat terbakar secara sempurna. Tingginya kadar mineral yang terkandung dalam biopelet kemungkinan diakibatkan oleh kandungan awal bahan baku kulit coklat yang mempunyai kadar mineral yang tinggi atau terlalu banyaknya penambahan air yang diberikan pada saat pembuatan biopelet.

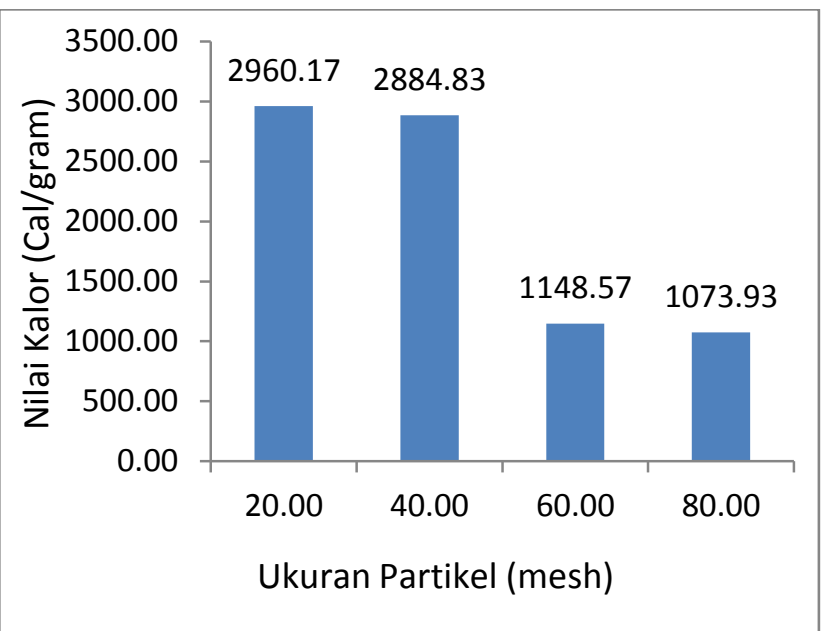

Gambar 10. Interval Nilai Kalor pada Pengaruh Pemberian Kadar Tapioka

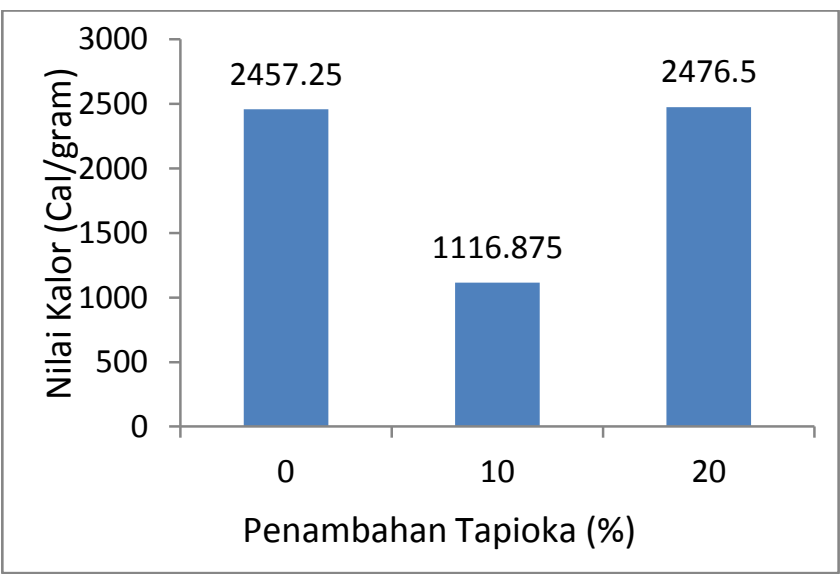

Gambar 11. Interval Nilai Kalor pada Pengaruh Pemberian Kadar Tapioka

\section{KESIMPULAN}

Perbedaan ayakan atau ukuran partikel biopelet memberikan pengaruh yang nyata terhadap nilai keteguhan tekan, kadar air, kadar abu, dan nilai kalor, namun tidak memberikan pengaruh yang nyata terhadap nilai kerapatan biopelet. Perlakuan optimal terjadi pada ukuran partikel biopelet 20 mesh dengan penambahan perekat tapioka $20 \%$ dengan kadar air 3,52\%, kadar abu 6,99\%, dan kerapatan $0,87 \mathrm{~g} / \mathrm{cm}^{3}$ dan nilai kalor 3090,1 kal/g. Pengembangan penelitian dapat diarahkan kepada penambahan campuran bahan baku yang mempunyai nilai kalor tinggi sehingga dapat meningkatkan nilai kalor biopelet yang dihasilkan. 


\section{DAFTAR PUSTAKA}

Ali A. dan Fajar, R. 2010. Optimasi Pembuatan Biopellets dari Bungkil Picung (Pangium edule Reinw) dengan Penambahan Solar dan Perekat Tapioka. Jurnal Sagu 9: 1-7.

AOAC, 2005. Official Methods of Analysis. Association of Official Analytical Chemists. Benjamin Franklin Station, Washington.

Bhattacharya SC. 1998. Appropriate biomass energy technologies: issues and problems. Renewable Energy Sources for Rural Areas in Asia and The Pacific. Japan: Tatsumi Printing Co., Ltd: 2653.

Badan Standarisasi Nasional. 2014. Pelet Kayu. Jakarta: SNI 8021:2014.

Christanty, N. Ari. 2014. Biopelet Cangkang Dan Tandan Kosong Kelapa Sawit Sebagai Sumber Energi Alternatif Terbarukan. Departemen Hasil Hutan, Fakultas Kehutanan, Institut Pertanian Bogor

Douard F. 2007. Chalange in the Expanding French Pellet Market. ITEBE Pellet 2007 Conference. Wells, Austria.

Hartadi, N. 2015. Pemanfaatan Limbah Tebu Menjadi Briket dan Biopelet. Skripsi. Departemen Teknologi Industri Pertanian. Fakultas Teknologi Pertanian. Institut Pertanian Bogor.

Haygreen JG, Bowyer JL. 1996. Hasil Hutan dan IImu Kayu. Sutjipto AH, penerjemah; Soenardi $\mathrm{P}$, editor. Yogyakarta (ID): Gajah Mada University Press. Terjemahan dari: Forest Product and Wood Science, an Introduction.

Lehmann B, Schroder HW, Wollenberg R, Repke JU. 2012. Effect of miscanthus addition and different grinding processes on the quality of wood pellets. doi:10.1016/j.biombioe.2012.05.009. Biomass Energy 44: 150-159

Merdekawani, S. dan Kasmiran, A. 2013. Fermentasi Limbah Kulit Buah Kakao (Theobroma Cacao L) dengan Aspergillus Niger Terhadap Kandungan Bahan Kering Dan Abu. LENTERA: Vol.13 No.2 Juni 2013.

Munawar, S. Sofyan dan B. Subiyanto. 2014. Characterization of Biomass Pellet Made
From Solid Waste Oil Palm Industry. Procedia Environmental Sciences 20 (2014) 336 - 341.

Nurwigha R. 2012. Pembuatan biopelet dari cangkang kelapa sawit dengan penambahan arang cangkang sawit dan serabut sawit sebagai bahan bakar alternatif terbarukan [skripsi]. Bogor (ID): Institut Pertanian Bogor.

Patabang, D. 2011. Studi Karakteristik Termal Briket Arang Kulit Buah Kakao. Jurnal Mekanikal, Vol. 2 No. 1: 23-31.

[PFI] Pellet Fuel Institute. 2007a. Pellets: Industry Specifics. http://www.peletheat.org/3/ industry/IndustrySpecifics.html.

Rahman. 2011. Uji Keragaan Biopelet dari Biomassa Limbah Sekam Padi (Oryza sativa sp.) Sebagai Bahan Bakar Alternatif Terbarukan [skripsi]. Bogor: Departemen Teknologi Industri Pertanian.

Saptoadi H. 2006. The Best Biobriquette Dimension and its Particle Size. The 2nd Joint International Conference on "Sustainable Energy and Environment (SEE 2006)"21-23 November 2006. Bangkok, Thailand.

Saragih AE. 2013. Karakteristik biopelet dari campuran cangkang sawit dan kayu sengon sebagai bahan bakar alternative terbarukan [skripsi]. Bogor (ID): Institut Pertanian Bogor.

Suparjo, Wiryawan KG, Laconi EB, Mangunwidjaja D. 2009. Perubahan komposisi kimia kulit buah kakao akibat penambahan mangan dan kalsium dalam biokonversi dengan kapang Phanerochaete chrysosporium. Media Peternakan. 32:203-210.

Zamirza F. 2009. Pembuatan biopelet dari bungkil jarak pagar (Jathropa curcas L.) dengan penambahan sludge dan perekat tapioka [skripsi]. Bogor (ID) : Institut Pertanian Bogor.

Winata, A. 2013. Karakteristik Biopelet Dari Campuran Serbuk Kayu Sengon Dengan Arang Sekam Padi Sebagai Bahan Bakar Alternatif Terbarukan. Skripsi. Institut Pertanian Bogor

Winata, A. 2013. Karakteristik Biopelet Dari Campuran Serbuk Kayu Sengon Dengan Arang Sekam Padi Sebagai Bahan Bakar Alternatif Terbarukan. Skripsi. Institut Pertanian Bogor 